\title{
Focus on focus groups
}

\section{By Vicki Young}

\section{A step-by-step guide to running focus groups}

ocus groups are one type of qualitative research. They are used to explore people's beliefs, perceptions, and attitudes about a certain topic. Focus-group research is becoming one of the most popular forms of market research.

The most common use of focus groups is at the beginning of a research project, usually followed up by survey or questionnaire (quantitative research).

They are called focus groups because the discussions start out broadly and gradually narrow down to the focus of the research. They are not a rigidly constructed question-and-answer session. Focus groups are used in a variety of situations often to test new product ideas and evaluate commercials.

Focus groups typically consist of $8-12$ people, with a moderator who focuses the discussion on relevant topics in a nondirective manner. Depending on the situation, homogeneous groups are often recommended, since various constituencies share concerns and views. For example, faculty expectations and perceptions of the library are often different than student views.

There has been an increase of focus group use in colleges and universities, and even libraries.

\section{Why use focus groups?}

Focus groups have several advantages over other forms of research. These advantages include:

- Participants use their own words to express their perceptions.

- Moderators ask questions to clarify comments.
- The entire focus-group process usually takes less time than a written survey.

- Focus groups offer unexpected insights and more complete information.

- In focus groups, people tend to be less inhibited than in individual interviews.

- One respondent's remarks often tend to stimulate others, and there is a snowball effect as respondents comment on the views of others.

- Focus-group question design is flexible and can clear up confusing responses.

- Focus groups are an excellent way to collect preliminary information.

- Focus groups often detect ideas that can be investigated further using quantitative research methods, such as a questionnaire.

\section{2 steps for successful focus groups}

1. Use moderators from outside the library. Moderating your own focus groups is like fixing your plumbing. It isn't as easy as it looks. More than anything else, the success of a focus group depends on the moderator.

You cannot moderate your own focus group for a number of reasons. Participants might be reluctant to discuss issues with you and it is impossible for you to be objective when you have a vested interest in the outcome.

2. Select moderators based on skills. They should have good communication skills and experience with group dynamics. In addition to having a healthy curiosity themselves, several very important skills/behaviors that moderators should have include:

- The ability to ask questions in ways that are not leading.

- The skill of knowing when to probe and ask for clarification.

- The restraint to resist reacting to participants' statements (no matter how erroneous). 
- The ability to involve those not participating.

- The skill of establishing rapport quickly.

- The ability to summarize areas of agreement and differences through paraphrasing.

- The ability to direct but not control the discussion

The moderator does not have to be an expert on the subject under discussion. The moderator must realize that focus groups are discussions and not question-and-answer sessions, and that the role of a focus group is not to educate

3. When recruiting, ask for volunteers. Screen participants for desired characteristics.

A good way to recruit volunteers is to send a brief questionnaire to your target population. Questions may include name, telephone, major, class standing, and how often they use the library. Include a question asking if they would be interested in participating in a librarywide study that would require two hours of their time. You may want to indicate that they would receive a small gift as a token of appreciation.

Try to get a representative sample from your target market. For example, if your campus has graduate students and undergraduates, be sure both of those groups are represented.

4. Use stratified groups. Separate faculty from students, undergraduates from graduate students. Do try to include all aspects of the target population, such as dorm, commuters, full-time, part-time.

Because you are trying to create an atmosphere that leads to self-disclosure, it is important to keep the groups homogeneous. It is also important that these focus groups represent each constituency.

5. Schedule 8-12 people per focus group, but overschedule, especially if using student groups. Send several reminders to participants of date, time, and place of session.

Using the recruiting forms, have someone call by phone and give participants several choices of time and day of the week.

Several days before the group is scheduled to meet, send reminder postcards and you may want to call them as another reminder the day before the scheduled focus group.

6. Schedule sessions for $1 \frac{1 / 2}{2}$ to 2 hours.

This is based on both experience and the literature. Since focus groups use a funnel effect, starting out broad and narrowing, ample time must be allowed for this process to happen.
7. Develop a good discussion guide based on goals and objectives of the research. Pretest the questions on a test sample and modify as needed. Even a quick pretest is likely to point out problems. The discussion guide should be short.

The design of the interview guide is crucial in the success of the focus groups. It is the interview guide that makes a focus group different from question-and-answer sessions or group discussions.

The interview guide should be designed as a projective technique, designed to deliberately stimulate a relaxed free-flow of associations and bypass people's built-in censoring mechanisms.

\section{discussion guides provided the information that we wanted: perceptions, attitudes, and beliefs about both the library's services and collections.}

\section{Run $3-4$ groups per target audience}

\section{for the best results.}

More than four groups will be overkill, and less than two may not provide enough data. Collecting information from a diverse population may require many group sessions, which can be time-consuming and costly.

Recruiting participants who represent your target population can be more difficult and timeconsuming than is immediately apparent.

9. Hold sessions in a centrally located, easy-to-find room. Use a room that allows for audiotaping and observation behind a two-way mirror.

You want a setting that will be relaxed and inviting. Seating should be carefully arranged. Participants at a small table with the moderator seated among the group is the best arrangement.

10. Reward participants for their time.

In industry, participants are usually paid for attending focus groups. If you don't have money, a certain dollar amount of free ILL or photocopying, or a mug filled with candy will serve as a token of appreciation.

11. In analyzing the data, look for trends or comments that are repeated in several sessions.

Analyze the sessions through the audiotape, flip chart paper, and your own observation 
notes. Compile and summarize the results for each session. Look for repeated trends or problems to study further.

12. Do not overgeneralize information gained from focus groups, and don't use it for policy decisions.

Because of the nonscientific sampling and the inability to quantify results, you need to use the information carefully. Focus groups should be followed up with statistically sound quantitative research.

\section{Like any tool, a focus group must be used correctly to obtain maximum benefit.}

\section{Cautions in using focus groups}

Like any tool, a focus group must be used correctly to obtain maximum benefit. It is inappropriate to try to gather quantitative data from focus groups, such as how many or how much. Instead use focus groups to answer how or why questions.

Remember: the information from a focus group may not accurately reflect the attitudes of the entire population; participants in focus groups are not necessary a representative sample; focus groups should be only part of the research process; and don't use the raw data as the basis for final decision making.

Focus groups can be misleading for several reasons. The most common reasons are the moderator's lack of questioning skills expertise, a bad discussion guide, and focus group participants who don't resemble the target market.

\section{Xavier's experience with focus groups}

After two years of constant change in the library including automating and renovating, the library staff wanted to know how the library was perceived by the students and faculty who use it.

So in the spring of 1990 we ran a series of focus groups at the suggestion of a friend who works at Procter and Gamble, a company known for their marketing expertise. We used the focus groups to identify strengths and problems, and to form a basis for questions for a follow-up written mail survey.

We used moderators from outside the $1 \mathrm{i}$ brary and ran a total of 24 groups ( 4 faculty, 6 graduate, and 7 undergraduate) over a threeweek period.

We used two different discussion guides, representing two approaches. Both were demonstrated by professional moderators. Our moderators could then choose the method they preferred.

One discussion guide was designed by my friend at Procter and Gamble and used brainstorming techniques to elicit attributes of an ideal library. Participants generated a list of library attributes important to them, and were then asked to choose their top three. For each of the top attributes, the Xavier library was rated in three categories: strong, okay, or should be improved.

The second discussion guide was developed by the chair of Xavier's Marketing Department who has been involved with numerous focus groups in the not-for-profit sector. His approach concentrated on people's impressions of Xavier's library: what they use the library for, what they like and dislike about the library, and what they would like to see different.

Both discussion guides provided the information that we wanted: perceptions, attitudes, and beliefs about both the library's services and collections. We pretested the discussion guides on a group of library staff and made the appropriate changes.

\section{What we learned}

On the positive side, the focus groups were good P.R. for the library. Students, especially, appreciated the chance to be heard and felt that we really cared enough to listen.

We did hear more positive than negative comments both from faculty and students. Both groups commented on the helpfulness of library staff, especially the reference librarians.

On the negative side, scheduling the groups was a nightmare. Between room availability, moderator availability, and guessing what would be good times for students and faculty, it was difficult to schedule the groups. Obviously we overcame the obstacles, having scheduled 24 groups.

It was alarming to hear widespread misconceptions. For example, one student thought that the library was only open four hours on Saturday. Students wanted services that the library actually had such as ILL fax service. Students and faculty had unrealistic expectations, such as the library should have all the journals indexed in all the CD-ROMs. 
It was very hard for the library staff to sit in the closet when they wanted to burst into the room to correct the erroneous information.

\section{Conclusion}

Focus groups, if conducted properly using the 12 steps presented, can provide a wealth of information. They are a good method for determining what issues and concerns should be addressed in follow-up quantitative research. Remember that focus groups are only one part of the research process.

\section{References}

Baker, Sharon L. "Improving Business Services Through the Use of Focus Groups." $R Q 30$ (Spring 1991) 377-385.

Hayes, Thomas J., and Carol B. Tathum (eds.). Focus Group Interviews: A Reader. Chi- cago: American Marketing Assoc., 1989.

Merton, Robert K., Marjorie Fiske, and Patricia L. Kendall. The Focused Interview: $A$ Manual of Problems and Procedures. New York: Free Press, 1990.

Morgan, David L. Focus Groups as Qualitative Research. Newbury Park, Calif: Sage Publications, 1988.

Stewart, David W., and Prem N. Shamdasani. Focus Groups: Theory and Practice. Newbury Park, Calif: Sage Publications, 1990.

Templeton, Jane Farley. Focus Groups: $A$ Guide for Marketing and Advertising Professionals. Chicago: Probus Publishing Co., 1987.

Widdows, Richard, Tia A. Hensler, and Marlaya H. Wyncolt. "The Focus Group Interview: A Method for Assessing Users' Evaluation of Library Service." College and Research Libraries 52 (July 1991) 353-359.
(Controversial materials cont. from page 388)

shows a high incidence of theft and mutilation. Many books like A Secret Garden or The Story of $O$ have been bought for the general collection, but replacement copies have been sent to reserve after experience has shown we cannot keep them safe in the stacks. For certain other materials, such as The Joy of Lesbian Sex, it seems foolish not to assume that the probability of theft is so high that we should not put the first copy on reserve and be done with it.

The general philosophy we have come to is that pragmatism can go a long way to defuse or deflect issues that are often injected with an overload of symbolic significance. Much as the identification of erotic materials with books on racquetball or chess serves to defuse a potentially controversial collection development issue, the location of highly sensitive materials on reserve is made less questionable by their sharing this designation with Billboard, Rolling Stone, and the used car price guides, which we have also determined cannot be kept secure in the general collection.

6) In retrospect, and in light of the thoughtful discussion available in the Intellectual Freedom Manual, our policy probably over-emphasizes erotic materials and should place more stress on matters of religious belief or political ideology. If we were to rewrite the policy and to see it through the twists and turns of the governance process, we would include a greater defense of diversity in collections. ALA's careful delineation of diversity as a goal, (in con- trast to the more cautious, yet inevitably more controversial goal of "balance") as laid out in section 2.6 of the Intellectual Freedom Manual, should be reflected in any future iteration of our policy. ${ }^{+}$

\section{Notes}

${ }^{1}$ Office for Intellectual Freedom of the American Library Association, Intellectual Freedom Manual fourth edition (Chicago: ALA, 1992), p. 39.

${ }^{2}$ American Library Association, ALA Policy Manual, pp. 136-159 of ALA Handbook of Onganization 1991/92 (Chicago: ALA, 1991), p. 153.

"Intellectual Freedom Manual, p. 66.

"Diversity in Collection Development," in Intellectual Freedom Manual, pp. 49-57.

\section{Share your library's news}

CERL News wants to hear about your library's activities. Information in the News from the Field, Grants \& Acquisitions, and People in the News columns is gathered from press releases and notices we receive. If you don't share your ideas and activities with us we can't share them with CERL News readers. Be sure to put CERL News on your mailing list today. Send notices to the Editor, CERL News, 50 E. Huron St., Chicago, IL 60611; or e-mail: U38398@uicvm.uic.edu. 